\title{
Direitos humanos e segurança internacional: uma análise sobre o conflito do Saara Ocidental
}

\author{
Human rights and international security: an analysis of the Western Sahara conflict
}

DOI: https://doi.org/10.22456/2178-8839.102698

Jéssica Moreira de Amorim Morais Universidade Federal do ABC, São Bernardo do Campo, Brasil jessica_morais01@yahoo.com.br

Julia Bertino Moreira Universidade Federal do ABC, São Bernardo do Campo, Brasil julia.bertino@ufabc.edu.br

\section{Resumo}

O regime internacional de proteção e promoção de Direitos Humanos foi se expandindo e se consolidando no âmbito das Nações Unidas (ONU) desde a metade do século XX até os dias atuais. Após a Guerra Fria, as questões de Direitos Humanos passaram a integrar a agenda da Segurança Internacional, como competência do Conselho de Segurança (CS) - o qual é responsável pela resolução de conflitos, como é o caso do Saara Ocidental. Durante o processo de ampliação da agenda da Segurança Internacional, foram cunhados dois princípios, distintos, porém que conversam bem entre si: segurança humana e responsabilidade de proteger. Ambos ajudaram a trazer os Direitos Humanos para o topo da agenda internacional. Este trabalho foca nestes princípios ao analisar a situação de direitos humanos no caso do Saara Ocidental em dois momentos específicos: antes e depois da ampliação da agenda da Segurança Internacional, equivalentes ao período durante o conflito armado (de 1975 a 1991) e ao período após o cessar-fogo (de 1991 até o momento). Utilizaremos como recursos metodológicos a pesquisa documental e revisão bibliográfica, tendo como base artigos acadêmicos, livros, documentos oficiais da ONU e relatórios de ONGs.

Palavras-Chave: Direitos Humanos; Saara Ocidental; Segurança Internacional.

\section{Abstract}

The international regime for the protection and promotion of Human Rights has been expanding and consolidating within the Framework of the United Nations (UN) from the middle of the 20th century to the present day. After the Cold War, human rights issues became part of the international security agenda, as the competence of the Security Council (CS) - which is responsible for conflict resolution, as is the case in Western Sahara. During the process of expanding the International Security agenda, two distinct principles were coined, but they talk well with each other: human security and the responsibility to protect. Both helped bring Human Rights to the top of the international agenda. This paper focuses on these principles when analyzing the human rights situation in the case of Western Sahara at two specific times: before and after the expansion of the International Security agenda, equivalent to the period during the armed conflict (from 1975 to 1991) and the period after the ceasefire (from 1991 to the present). We will use documentary research and bibliographic review as methodological resources, based on academic articles, books, official UN documents and NGO reports.
\end{abstract}

Keywords: Human rights; Western Sahara; International Security. 


\section{Introdução}

O regime ${ }^{1}$ internacional de proteção e promoção de Direitos Humanos foi construído sobretudo após a Segunda Guerra Mundial e sendo modificado nas décadas posteriores, especialmente no âmbito das Nações Unidas (ONU). Até o fim da Guerra Fria, este regime sofreu muitas resistências no sistema internacional, visto que o pensamento hegemônico tradicional era pautado nos Estados como atores principais, relegando temas de Direitos Humanos à segurança doméstica e não como um fator de Segurança Internacional (GHISLENI, 2011). Quando este pensamento passou a ser substituído, especialmente no pós-Guerra Fria, os assuntos de Direitos Humanos começaram a integrar o rol de problemas relacionados à Segurança Internacional, aumentando assim sua relevância (BUZAN; HANSEN, 2012).

Esse movimento vai se consolidando dentro da agenda securitária paulatinamente mediante esforços dentro da ONU, particularmente encabeçados por seus Secretários-Gerais (GHISLENI, 2011). Como parte destes esforços, destaca-se o relatório do PNUD de 1994, responsável por desenvolver as bases empíricas do conceito de segurança humana - o qual foi crucial para consolidar uma ideia global de proteção e promoção de Direitos Humanos como fator de Segurança Internacional e, portanto, responsabilidade da comunidade internacional (BUZAN; HANSEN, 2012).

Em consonância com essas mudanças criou-se, em 1999, o princípio da responsabilidade de proteger (R2P). Este reforça a ideia de que a comunidade internacional tem a responsabilidade de intervir a fim de garantir a segurança humana, caso o Estado individualmente não o faça ou a viole, sendo o Conselho de Segurança (CS) o órgão com a incumbência de decidir e realizar intervenções de caráter humanitário (GHISLENI, 2011). Essa discussão reverbera para inúmeros casos de conflitos no mundo contemporâneo, como o do Saara Ocidental, ainda em curso.

O conflito do Saara Ocidental se iniciou na década de 1970 e já dura mais de 40 anos. Apesar de ser um conflito de longa duração, que envolve diversos aspectos possíveis de serem analisados, o mesmo tem tido pouca visibilidade no cenário internacional. As produções acadêmicas no Brasil $^{2}$ a respeito do caso são escassas se comparadas às estrangeiras ${ }^{3}$. Ainda assim, encontrar materiais que tratam do conflito do Saara Ocidental ou dados concretos e precisos permanece um desafio. Existem publicações ${ }^{4}$ sobre a situação dos Direitos Humanos da população saaraui, pautando-se por outras perspectivas distintas da que abordamos nesta análise. O presente artigo busca contribuir para suprir tal lacuna bibliográfica, assim como para aumentar a visibilidade do caso do Saara Ocidental, ao enfocar a relação da questão dos Direitos Humanos com a ampliação da agenda de Segurança Internacional e os impactos que tais mudanças tiveram no conflito em tela. É fato que o conflito evoluiu e se estendeu concomitantemente ao desenvolvimento do regime internacional de Direitos Humanos no decorrer das referidas décadas. Todavia, o conflito continua irresoluto e a população saaraui ainda sofre violações sistemáticas de Direitos Humanos.

Este trabalho analisa se os princípios da segurança humana e responsabilidade de proteger têm sido respeitados no caso do Saara Ocidental e se houve alteração na situação de violação de Direitos Humanos da população saaraui após a entrada da questão dessa temática no rol de Segurança Internacional. Para tanto, estudamos a situação dos Direitos Humanos no território antes e depois da ampliação da agenda securitária a fim de comparar os dois momentos, especialmente aquele em que existia o conflito armado (1975 a 1991) e após o cessar-fogo (1991 até o momento), com foco para a atuação do CS no caso.

Em termos metodológicos, utilizamos a pesquisa documental e revisão bibliográfica, baseando-nos em artigos acadêmicos, livros, documentos oficiais da ONU e relatórios elaborados por ONGs. O texto está dividido da seguinte forma: a primeira seção traz um panorama da questão dos Direitos Humanos no regime global da ONU e os princípios da

\footnotetext{
${ }^{1}$ Segundo Krasner (1982, p. 186, tradução nossa), "regimes podem ser definidos como um conjunto de princípios, normas e regras implícitos ou explícitos e procedimentos de tomada de decisões de determinada área das relações internacionais em torno dos quais convergem as expectativas dos atores". No original: "regimes can be defined as sets of implicit or explicit principles, norms, rules, and decision-making procedures around which actors' expectations converge in a given area of international relations".

${ }^{2}$ Consultar: Daudén e Suzin (2011), Duarte (2016), Estrada (2014), Ferreira e Migon (2015) e Smoralek (2013). Ver mais em: Santayana (1987).

${ }^{3}$ Entre as obras estrangeiras estão: Barata (2012), Es-Sweyih (2001), Miguel (1995). Ver mais em: Besenyó (2008).

${ }^{4}$ Alguns artigos científicos que tratam dos Direitos Humanos da população saaraui são: Beristain e Hidalgo (2012) e García (2014). Também há relatórios produzidos por ONGs, embora não sejam produções acadêmicas.
} 
segurança humana e da responsabilidade de proteger, relacionando-os com a ampliação da pauta de Segurança Internacional. A segunda seção apresenta um panorama histórico sobre o Saara Ocidental e a origem do conflito a fim de melhor contextualizar o leitor a respeito do caso em estudo. A terceira seção trata, por fim, do conflito em seus dois momentos: durante o conflito armado, que começa na década de 1970, no cenário da Guerra Fria; e após o cessar-fogo em 1991 até os dias atuais.

\section{Direitos Humanos: regime global da ONU}

O regime global ${ }^{5}$ de Direitos Humanos começou a ser instituído após a criação da ONU em 1945, no contexto do pós-Segunda Guerra, a qual tem como um de seus principais objetivos manter a paz mundial. No âmbito desta organização, em 1948, estabeleceu-se a Declaração Universal dos Direitos Humanos (DUDH), a qual, embora sem força jurídica vinculante, é considerada o pontapé inicial da construção deste regime internacional. O mesmo hoje conta com diversos instrumentos legais, como exemplos: o Pacto Internacional dos Direitos Civis e Políticos (PIDCP, 1966) e o Pacto Internacional sobre os Direitos Econômicos, Sociais e Culturais (PIDESC, 1966). Além disso, também dentro deste escopo, podem ser mencionadas as Convenções de Genebra de 1949, bases do Direito Internacional Humanitário (DIH), e a Convenção de Genebra de 1951 relativa ao Estatuto dos Refugiados, entre vários outros instrumentos que tratam de temáticas relacionadas a Direitos Humanos (FIELDS, 2003).

No sistema ONU, existem órgãos especializados para tratar dos conteúdos de Direitos Humanos como: o Conselho de Direitos Humanos da ONU, os Procedimentos Especiais (Relatores Especiais, alguns Grupos de Trabalho e Especialistas Independentes) e o Escritório do Alto Comissário das Nações Unidas para os Direitos Humanos (ACNUDH) (ONU, 2019). Porém, estes órgãos não têm força punitiva e, em geral, o seu trabalho é de colaboração, denúncia e recomendação. O DIH e o Direito Internacional dos Refugiados (DIR) também contam com agências e órgãos especializados no sistema ONU, tendo sido criado, no caso do primeiro, o Tribunal Penal Internacional (1998, em vigor desde 2002), responsável por julgar crimes de genocídio, crimes de guerra, crimes contra a humanidade e crimes de agressão (GHISLENI, 2011).

Apesar da construção dessas diversas instituições e de mecanismos legais, a questão dos Direitos Humanos enfrentou resistências por parte dos Estados ao confrontar o princípio da soberania, visto que as violações a estes direitos fundamentais ocorrem em âmbito nacional. Por este motivo, até a metade do século XX, tal questão era tratada dentro da lógica da segurança nacional (GHISLENI, 2011; BUZAN; HANSEN, 2012). Porém, o próprio conceito de segurança foi sendo modificado com o tempo, o que gerou impactos no tratamento dado aos Direitos Humanos em nível internacional - como veremos a seguir.

\section{Segurança Internacional e Direitos Humanos}

O conceito de segurança, até o fim da Guerra Fria, foi pautado pela visão clássica/tradicional focada no paradigma westfaliano, ou seja, na soberania dos Estados. Priorizava-se o poderio militar e a não intervenção em assuntos internos, motivo pelo qual a segurança internacional não raro era tida como sinônimo de segurança nacional (BUZAN; HANSEN, 2012). Com o pós-Guerra Fria, surgiu uma corrente teórica que confrontava o pensamento tradicional: os ampliacionistas. Esta se pautava pelo contexto da época, em que se intensificaram os conflitos internos, o acirramento da devastação ambiental, assim como de epidemias, entre outros fatores que também colocavam em risco a segurança internacional e não eram considerados pelos tradicionalistas. Dentro desse alcance maior de ameaças à segurança internacional, também

\footnotetext{
${ }^{5}$ Focaremos no regime de Direitos Humanos em âmbito global, devido à limitação de espaço, pois não seria possível incluir a discussão sobre regimes regionais - tendo especial interesse aqui o africano - , o que renderia uma discussão à parte.
} 
foram incluídas as violações sistemáticas de Direitos Humanos, tendo impacto regional ou global, as quais não seriam, assim, de responsabilidade exclusiva do Estado em âmbito doméstico (BUZAN; HANSEN, 2012).

O processo de ampliação da agenda foi se dando de maneira gradual como resultado de um longo processo de debate acadêmico iniciado após o fim da Segunda Guerra Mundial e contando com o engajamento de instituições como organismos internacionais e ONGs. Nesse contexto, destaca-se o relatório do PNUD de 1994, responsável por desenvolver as bases empíricas para o conceito de segurança humana. Tal formulação conceitual foi crucial para o regime de Direitos Humanos, pois consolidou uma ideia global de proteção e promoção dos mesmos como fator de segurança internacional e, portanto, de responsabilidade da comunidade internacional (BUZAN; HANSEN, 2012).

Ao romper de vez com o objeto de referência focado no Estado, a noção de segurança humana lança luz para o indivíduo como sujeito de segurança, embora seja o Estado o meio garantidor dos direitos desse indivíduo. De acordo com o referido relatório, o conceito diz respeito a manter as pessoas seguras de ameaças crônicas como a fome, doenças, repressões, violações de Direitos Humanos e protegê-las das guerras, dos genocídios e das limpezas étnicas. Abarca, com isso, a segurança econômica, alimentar, sanitária, política, comunitária, pessoal e ambiental. Portanto, tal conceito abrange diversos âmbitos da vida e clama pelo respeito aos Direitos Humanos como crucial para a segurança de todos (PNUD, 1994; OLIVEIRA, 2009).

Entre as iniciativas políticas concretas alinhadas à concepção do PNUD se encontra o Fundo Fiduciário para a Segurança Humana. Este foi encabeçado pelo Japão em 1999, com o intuito de apoiar as instituições da ONU e em seguida o país também liderou uma Comissão sobre Segurança Humana na ONU. Entretanto, em crítica à concepção abrangente do PNUD, em 1998, foi elaborada a concepção restrita, proposta pelo governo canadense. Esta última foca na "proteção diante da violência física em contextos de conflitos armados e crises humanitárias” (OLIVEIRA, 2009, p. 73), dando origem à Rede de Segurança Humana (1999), através de acordo bilateral entre Canadá, Noruega e Suíça. Esta tem como objetivo “promover políticas comuns de Segurança Humana numa série de instituições internacionais e regionais" (OLIVEIRA, 2009, p. 74). Em que pesem tais modificações e iniciativas, o conceito ainda é criticado por parte de acadêmicos, sobretudo em relação à sua operacionalidade na prática (OLIVEIRA, 2009).

Ao incluir os Direitos Humanos no âmbito da Segurança Internacional, o CS também passou a ser envolvido diretamente, por ser o órgão responsável pela manutenção da paz e por determinar quais são as ameaças à segurança internacional conforme o Artigo 39 da Carta da ONU. Na realidade, o CS sempre teve como uma de suas obrigações considerar os Direitos Humanos em suas ações (Cap. I e VII), porém havia um choque entre os limites impostos à ONU pela própria Carta da instituição, diante do princípio da não-intervenção em assuntos nacionais, disposto em seu Artigo $2^{\circ}$, parágrafo $7^{\circ}$, o que limitava a atuação do CS. No entanto, com a articulação dos Direitos Humanos à agenda securitária, foi possível reinterpretar este princípio a fim de evitar sua invocação para impedir a intervenção do CS em questões humanitárias (GHISLENI, 2011).

Nesse cenário, foi notável o crescimento das intervenções de caráter humanitário aprovadas pelo CS e espalhadas pelo mundo a partir da década de 1990, visto que o número de conflitos internos passou a aumentar, assim como o envolvimento da população civil nos mesmos. Estas intervenções humanitárias ${ }^{6}$ se tornaram importantes mecanismos para a proteção de civis em situação de conflito e a pacificação de áreas consideradas instáveis, em que havia possibilidade de eclodir novos conflitos (DUARTE, 2015).

A demanda pela atuação do CS em matéria de Direitos Humanos se consolidou com a atuação do ex-Secretário Geral Kofi Annan, sobretudo ao instituir, em 2005, o princípio da responsabilidade de proteger (responsability to protect ou R2P) ${ }^{7}$. Esse conceito foi cunhado pela Comissão Internacional sobre Intervenção e Soberania Estatal (ICISS, na sigla em

\footnotetext{
${ }^{6}$ Devido à frequência das intervenções humanitárias, foi criado um princípio que consolidaria essas ações para garantir a Segurança Internacional, o princípio da Responsabilidade de Proteger, que veremos a seguir (DUARTE, 2015)

${ }^{7} \mathrm{O}$ conceito se consolida, em 2005 no âmbito da Assembleia Geral da ONU, através da declaração World summit outcome document, porém sua formulação teve início em 2001(KENKEL, 2012).
} 
Inglês), uma instituição de iniciativa canadense e vinculada à ONU. Em 2001, após debates com representantes de Estados, ONGs e instituições internacionais, a comissão publicou um estudo chamado “Responsibility to Protect” (DUARTE, 2015). Conhecido como 'R2P', afirma ser prioridade do Estado "proteger a sua população do genocídio, crimes de guerra, limpeza étnica e todos os outros crimes contra a humanidade, e necessita que a comunidade internacional intervenha caso essa obrigação não seja cumprida” (ONU, 2019).

O R2P pode ser dividido em três pilares: a responsabilidade de prevenir, a responsabilidade de reagir e a responsabilidade de reconstruir. A responsabilidade de prevenir se refere às medidas que devem ser tomadas a fim de amenizar ou acabar com instabilidades que possam levar a conflitos, evitando, assim, a posterior intervenção humanitária. Caso as medidas de prevenção não sejam suficientes, aplica-se a responsabilidade de reagir, ou seja, o emprego de medidas intervencionistas. Nesse caso, a comunidade internacional deveria intervir com métodos não coercitivos e, caso não funcionassem, caberia ao CS adotar métodos coercitivos. Após as medidas intervencionistas, a comunidade internacional tem a responsabilidade de reconstruir, ou seja, auxiliar o Estado que passou pelo processo de intervenção a retomar a estabilidade, a fim de evitar a eclosão de novo conflito. Um exemplo disso, segundo a referida comissão, seriam as operações de manutenção de paz da ONU (ICISS, 2001).

No entanto, havia objeções ao princípio R2P feitas por Estados do Sul global, como Brasil, Índia, Cuba, Síria, Sudão e Irã. Em resposta, a ONU e os apoiadores deste princípio afirmaram haver uma "responsabilidade residual e vestigial da comunidade internacional, que entraria em efeito unicamente depois de completamente esgotadas todas as outras possíveis tentativas de fortalecer a soberania vertical do Estado em questão” (KENKEL, 2012, p. 42). Porém, as preocupações destes Estados foram confirmadas com o desenrolar de algumas intervenções humanitárias, como por exemplo, a Guerra do Iraque em 2003 e a intervenção na Líbia em 2011, em que grandes potências, como os Estados Unidos e o Reino Unido, utilizaram o princípio R2P como meio para atingir seus interesses militares (STUENKEL; TORINHO, 2014).

Como reação aos abusos cometidos mobilizando o conceito do R2P, em 2011, o governo brasileiro, tendo a então presidente Dilma Rousseff como porta-voz, apresentou um novo princípio ao cenário internacional: o da responsabilidade ao proteger (responsability while protecting ou RwP). Este princípio reconhece as limitações e os problemas da $\mathrm{R} 2 \mathrm{P}$, como as falhas nas intervenções humanitárias em proteger os civis e o uso das mesmas de forma inapropriada e para outros propósitos, como políticos, por exemplo (STUENKEL, 2013). O RwP propôs o cumprimento efetivo do objetivo das intervenções, com a devida prestação de contas sobre suas atividades, um maior enfoque e engajamento em prevenção a conflitos, reduzindo a necessidade de uso posterior da força, entre outras propostas visando complementar a R2P e garantir maior transparência e controle nas intervenções humanitárias. Contudo, tal princípio ainda é recente e requer mais pesquisas para aferir sua aplicação na prática (QUINTON-BROWN, 2013).

Como vimos, tem restado cada vez mais patente a atuação do CS em temas vinculados ao regime internacional de Direitos Humanos, particularmente após a elaboração do conceito de segurança humana e do princípio de responsabilidade de proteger. Estudaremos adiante se os Direitos Humanos da população saaraui têm sido respeitados após as mudanças consolidadas mediante a ampliação da agenda de Segurança Internacional, especialmente com a instituição das novas chaves conceituais referidas acima.

\section{Antecedentes do conflito}

O território do Saara Ocidental $^{8}$ foi colônia espanhola, sendo que o processo de colonização promoveu a sedentarização, escolarização e urbanização das tribos nômades que ali viviam. Naquele momento, deu-se início à construção da identidade e consciência de uma comunidade supra tribal. Posteriormente, a defesa territorial tornou-se um

\footnotetext{
${ }^{8}$ Localizado na costa norte da África Setentrional e banhado pelo Oceano Atlântico. Faz fronteira com a Mauritânia ao leste e ao sul, com o Marrocos ao norte e com a Argélia no extremo nordeste. Tem uma superfície de 266,000km², predominantemente desértica.
} 
assunto pertinente a todas as tribos que povoavam o Saara Ocidental, fazendo com que surgisse um sentimento de pertencimento a um mesmo povo, ou seja, a ideia de nacionalismo. Isso desembocou em manifestações contra o domínio espanhol no território e posteriormente na luta por independência política (BARATA, 2012).

Em 1963, a ONU se envolveu na questão ao caracterizar o Saara Ocidental como um dos territórios enquadrados na Declaração sobre a Concessão da Independência aos Países e povos Coloniais, nos moldes da Resolução da Assembleia Geral (AG) 1514 [XV] de 1960. Conforme esta resolução, a população saaraui ${ }^{9}$ teria o direito de escolher entre: a independência do território, tornando-se um Estado; a livre associação à Espanha, em que teria o direito de determinar a sua própria constituição; e a integração à Espanha, em que as leis e direitos deveriam ser os mesmos entre os dois territórios. Para a tomada de decisão, seria necessário um referendo em que os próprios saarauis pudessem decidir como seria o futuro do seu território (AG, 1960).

A Espanha vivia um momento de fragilidade interna e fez diversas tentativas para não se desfazer do território. Entretanto, estas tentativas só fizeram crescer o sentimento nacionalista saaraui, com a emergência de movimentos nacionalistas organizados. Apesar dos esforços espanhóis para contê-los, estes movimentos se concretizaram em 1973, com a criação da Frente para a Liberação de Saguia-el-Hamra e Río de Oro (Frente Polisário) ${ }^{10}$. Segundo o seu estatuto, o objetivo era conquistar a independência e formar o Estado nacional saaraui, tendo sido declarada guerra à Espanha logo após a fundação da frente (MIGUEL, 1995).

Em 1974, devido às pressões da ONU, a Espanha fez um censo da população nativa para realizar o referendo, entretanto este não ocorreu devido às reclamações sobre o território saaraui por parte do Marrocos. Este alegava que o território lhe pertencia e, portanto, a independência não poderia ser uma das opções na votação. Com a intenção de ganhar tempo, o rei marroquino Hassan II solicitou que a Espanha adiasse a realização do referendo. Além disso, solicitou que a Corte Internacional de Justiça (CIJ) analisasse os vínculos jurídicos entre o Saara Ocidental, a Mauritânia e o Marrocos (Resolução 3292 [XXIX]) (BARATA, 2012).

Em 1975, a CIJ concluiu que o território do Saara Ocidental era habitado por diversas tribos e que de fato algumas delas tinham relações jurídicas com a Mauritânia e o Marrocos. Contudo, estes laços não eram suficientes para impedir o processo de autodeterminação da população saaraui. Sabendo da decisão, o monarca marroquino promoveu a "Marcha Verde”, episódio em que 350.000 marroquinos, escoltados pelas Forças Armadas Reais (FAR), ocuparam a região norte do Saara Ocidental. Naquele momento, a Espanha não tinha condições internas de enfrentar um conflito contra o Marrocos, portanto, cedendo às pressões marroquinas, aceitou assinar um acordo secreto com o mesmo e a Mauritânia, conhecido como Acordo Tripartite de Madrid (Acordo de Madrid) (ESTRADA, 2014) - o que foi considerado o estopim do conflito no Saara Ocidental.

\section{O conflito armado}

Assinado em 14 de novembro de 1975 pela Espanha, Marrocos e Mauritânia, o Acordo de Madrid estabeleceu a divisão da administração do Saara Ocidental entre os três países, porém a Espanha continuaria administrando o território, temporariamente, até 1976 (ESTRADA, 2014). Contudo, tal acordo não tem reconhecimento jurídico, sendo considerado ilegal pelo Direito Internacional, por contrariar o direito à autodeterminação do povo saaraui (SMOLAREK, 2012) e ignorar totalmente a decisão do CIJ. Portanto, o mesmo representa violação ao direito à autodeterminação dos povos, garantido pelo artigo $1^{\circ}$ da Carta da ONU e artigo $1^{\circ}$ do PIDCP - pacto este ratificado pelo Marrocos em 1979.

\footnotetext{
${ }^{9}$ Escolhemos utilizar o nome saaraui, em Português, embora a forma mais conhecida seja em Espanhol, saharaui.

${ }^{10}$ Esse movimento político e militar surgiu para lutar contra o domínio colonial e se tornou, a partir de então, o movimento oficial de libertação saaraui, sendo até hoje o representante oficial da nação (JUSTO, 2013).
} 
Logo após a assinatura deste acordo, teve início o conflito bélico entre as potências ocupantes e a Frente Polisário. Em 1976, a Espanha se retirou do território, levando a Frente Polisário a proclamar a República Árabe Saaraui Democrática (RASD) a fim de buscar apoio internacional e reivindicar a soberania do território (ESTRADA, 2014). Seguindo o contexto internacional da Guerra Fria, foram feitas as seguintes alianças: de um lado, o Marrocos e a Mauritânia recebiam apoio e ajuda de potências ocidentais, especialmente Estados Unidos da América (EUA) e França; de outro, a Frente Polisário tinha apoio de Estados como a Argélia - rival do Marrocos na hegemonia regional -, Cuba, Líbia e Vietnã, ou seja, indiretamente da União das Repúblicas Socialistas Soviéticas (URSS).

A Mauritânia deixou o conflito e desocupou o território em 1979, por adversidades internas, e firmou acordo de paz com a Frente Polisário. Diante disso, o Marrocos avançou sua ocupação para o território desocupado pela Mauritânia, que deveria ser controlado pela Frente Polisário. O conflito se acirrou e, para evitar os bem-sucedidos ataques da Frente Polisário, o Marrocos começou a construção de um muro defensivo em 1981, o qual foi finalizado em 1987 - conhecido popularmente como "The Berm” (SMOLAREK, 2012, p.36).

O muro tem em torno de 2.700 quilômetros de extensão e 3 metros de altura e dividiu o território em duas zonas: as Zonas Ocupadas, sob domínio marroquino, ocupando cerca de 85\% do território; e as Zonas Liberadas, controladas pela Frente Polisário (DAUDÉN; SUZIN, 2011) ${ }^{11}$. Além disso, conta "com um complexo de segurança com radares, cercas de arame farpado, minas terrestres, além do contingente militar que monitora todas as atividades da região" (ESTRADA, 2014, p. 130). Para realizar a edificação deste muro, o Marrocos contou com o apoio técnico e econômico dos EUA (LÓPEZ, 2012). Além de restringir o direito de ir e vir da população saaraui (o que configura violação ao artigo 13 da DUDH), o muro foi responsável pela separação forçada de muitas famílias saarauis (violação ao artigo 12 da DUDH e ao artigo 23 do PIDCP) e coloca a vida dessa população em risco devido às minas espalhadas ao seu redor, especialmente do lado das Zonas Livres (UM FIO... 2017).

Dada a longa duração do conflito, a população civil que não participava diretamente do mesmo - especialmente mulheres, crianças e idosos - viu-se obrigada a migrar para o deserto em direção às fronteiras argelinas, tendo sido acolhida pelo governo da Argélia e se estabelecido nos acampamentos de refugiados em Tindouf. O principal motivo do deslocamento foi o medo dos bombardeios marroquinos aéreos de fósforo branco e napalm, das prisões arbitrárias (caracterizando violação ao artigo 9 do PIDCP e a Convenção contra Tortura) e outras formas de violência utilizadas pelas FAR contra os civis. Segundo Cobo e Menéndez (2006), estas ações geraram um terror na população saaraui, a qual se viu forçada a fugir para sobreviver.

Durante o percurso rumo à Argélia, os saarauis se instalaram em acampamentos provisórios, construídos pela Frente Polisário, principalmente nas cidades de Amgala, Guelta, Zemmur, Um Dreiga e em Tifariti, localizados em lugar es estratégicos devido à existência de poços de água e fortificações militares abandonadas pelos espanhóis (COBO; MENÉNDEZ, 2006). Apesar disso, as FAR promoveram ataques aéreos com napalm e fósforo branco nos acampamentos de Tifariti e Guelta e posteriormente o ataque mais conhecido, promovido em Um Dreiga, que resultou em inúmeras vítimas civis (BOUKHARI, 2004).

O uso de armas químicas constitui uma violação ao direito à vida, sendo proibido pelo DIH, com base nas Convenções de Genebra de 1949. Além disso, durante conflitos armados, é proibido o ataque a civis, assim como a unidades médicas - identificadas com o símbolo da Cruz Vermelha -, pessoas da área médica e os poços de água. Os ataques desrespeitam, assim, normas do DIH, as quais protegem unidades e pessoas da área da saúde, bem como a população civil, especialmente mulheres e crianças - segundo o artigo $3^{\circ}$ comum a todas as referidas Convenções. O Marrocos as ratificou em 1956, e, portanto, deveria segui-las face ao compromisso jurídico firmado. Em que pese a violação dos tratados de

\footnotetext{
${ }^{11}$ Com esse muro, o Marrocos dominou 85\% do território - parcela que dispõe de diversos recursos naturais, além de estar numa posição estratégica - , deixando para a nação saaraui as Zonas Liberadas (15\%), uma região desértica e quase inabitável por causa das minas explosivas (ESTRADA, 2014).
} 
Genebra, o país não recebeu nenhum tipo de julgamento e decorrente punição por estes ataques, seja por parte de órgãos vinculados à $\mathrm{ONU}$, seja por parte de outras instituições internacionais ${ }^{12}$.

O conflito armado se estendeu por dezesseis anos, durante os quais foram sendo construídos os acampamentos de refugiados em território argelino e o Marrocos seguiu com os avanços na ocupação do território. Até então, a lógica no cenário internacional era pautada pelo pensamento tradicional e a comunidade internacional não havia assumido a responsabilidade de proteger ou garantir a segurança humana a indivíduos ou populações como a saaraui. A partir da década de 1990, iniciam-se as mudanças anteriormente apontadas na agenda securitária, momento que coincide com o início do cessar-fogo assinado em 1991, como veremos a seguir.

\section{Do cessar-fogo até o momento}

A assinatura do acordo de paz foi possível graças aos esforços da ONU e da Organização da Unidade Africana $(\mathrm{OUA})^{13}$. Ambas as organizações já tinham proposto o Plano de Ajuste ${ }^{14} \mathrm{em} 1988$ que visava solucionar o conflito - a partir do qual ocorreu o cessar fogo, entrando em vigor em 6 de setembro de 1991. O Plano de Ajuste ${ }^{15}$ previa a realização do referendo em que a população saaraui decidiria entre ser independente ou anexar-se oficialmente ao Marrocos, o que deveria ocorrer em 1992. Para tanto, foi criada a Missão das Nações Unidas para o referendo no Saara Ocidental (MINURSO) em 1991.

Dentre as diversas atribuições da MINURSO, estão: monitorar o cessar-fogo, supervisionar as trocas de prisioneiros de guerra; repatriar refugiados; e, como seu principal objetivo, organizar e realizar o referendo em que a população saaraui decidiria de forma justa entre as duas opções citadas acima, cabendo à MINURSO identificar e registrar os votantes (CONSELHO DE SEGURANÇA, 1991). O referendo não ocorreu devido ao impasse entre as partes sobre os votantes.

Em 1996, Kofi Annan foi eleito Secretário-Geral das Nações Unidas e nomeou James Baker como seu enviado especial ao Saara Ocidental em 1997. Novas negociações foram feitas e firmados os Acordos de Houston, que, em teoria, teriam resolvido as divergências entre as partes, como os eleitores que participariam do referendo. Porém, não foi o que se deu e novamente o dilema da identificação dos eleitores paralisou os avanços no processo (COBO, 2011). Em meados de 1999, o rei Hassan II faleceu e seu filho Mohamed VI ascendeu ao trono marroquino. Sendo assim, as negociações foram retomadas, porém as partes não entraram em acordo, pois, mais uma vez, não havia consenso sobre os eleitores que participariam da votação (DUARTE, 2016).

A divergência quanto à identificação dos eleitores no processo do referendo é o maior obstáculo à sua concretização. A princípio, havia sido acordado utilizar o censo realizado pela Espanha em 1974 como base para definir os votantes. Entretanto, o Marrocos em vários momentos pediu a inclusão de mais nomes nessa lista, especificamente dos marroquinos que migraram para o território do Saara Ocidental durante o processo de ocupação. A Frente Polisário discordou desta demanda, entendendo que os eleitores deveriam ser aqueles que residiam no território antes da ocupação marroquina (BARATA, 2012).

Em 2007, o CS convocou ambas as partes para negociarem diretamente sob o monitoramento da ONU. Contudo, não foi possível chegar a um acordo, visto que: de um lado, o Marrocos não queria renunciar ao território e, do outro lado, a Frente Polisário insistia na realização do referendo, com a opção de independência (DUARTE, 2016). Ocorreram outras

\footnotetext{
${ }^{12}$ À época ainda não existia o TPI. Tampouco foi criado algum tribunal ad hoc para julgar as violações.

${ }^{13}$ A OUA, atual União Africana, reconhece a RASD como um de seus Estados-membros. A entrada da RASD na OUA foi o motivo pelo qual o Marrocos decidiu sair da organização em 1984. A organização defende o direito à autodeterminação da população saaraui. Entretanto, o Marrocos foi readmitido na organização em 2017 e não sabemos que rumo essa mudança dará ao posicionamento da organização sobre a questão.

${ }^{14}$ Plan de Arreglo ou Settlement Plan em Espanhol e Inglês, respectivamente. O nome do plano em Inglês é muito utilizado nas literaturas a respeito, ao invés de utilizar tradução para o Português como escolhemos.

${ }^{15}$ Informes S/21360 (1990) e S/22464 (1991) (CONSELHO DE SEGURANÇA, 1990; 1991).
} 
rodadas de negociação sob a supervisão da ONU ou como conversações informais para tratar do cessar-fogo, pois episódios de violência continuaram a ocorrer, como o caso dos acampamentos de Gdeim Izik, nas Zonas Ocupadas, criado em 2010, protesto pela independência promovidos pelos saarauis e reprimido violentamente pelas FAR (GIMÉNEZ, 2014)

Dentro das Zonas Ocupadas sob o domínio marroquino, são inúmeras as denúncias por parte de ONGs, entre elas a Anistia Internacional e Human Rights Watch, que retratam casos de repressão, tortura, sequestros relâmpagos, prisões arbitrárias, entre outras formas de violência realizadas pelas FAR, violando disposições do PIDCP e da Convenção sobre a Tortura e da Declaração Universal de Direitos Humanos. Em um dos relatórios da Anistia Internacional publicado em 2015, foram relatados 173 casos de tortura e outros tipos de maus tratos praticados pelas forças de segurança do governo marroquino no Marrocos e no Saara Ocidental, no período de 2010 a 2014 . Demonstrando um comportamento hostil por parte do governo marroquino, além de um padrão de violação sistemática de Direitos Humanos, a ONU chegou a questionar o Marrocos, porém o governo negou as acusações e nada mais foi feito a respeito (ANISTIA INTERNACIONAL, 2015).

Em 2010, ocorreu o ato de maior repercussão internacional referente aos acampamentos de Gdeim Izik, construídos por aproximadamente 20 mil saarauis, para protestar em favor da independência. Passados alguns dias do início do protesto, os militares marroquinos invadiram Gdeim Izik e atacaram violentamente a todos, utilizando jatos de água quente, gás lacrimogêneo e armas de fogo. Saarauis foram encarcerados e torturados ${ }^{16}$, sendo que quem conseguiu fugir sofreu forte represália marroquina e teve de se esconder temporariamente (BERISTAIN; HIDALGO, 2012).

De acordo com o relatório emitido pela Associação de Cooperação e Solidariedade entre os Povos - ACOSOP (ACOSOP, 2013), referente ao julgamento de 25 presos saarauis relacionados ao Gdeim Izik, as torturas continuaram acontecendo, todos os presos estavam gravemente afetados e todos declararam já ter sofrido tortura física, psicológica e/ou sexual. A tortura é uma grave violação do artigo $5^{\circ}$ da DUDH, bem como ao artigo $7^{\circ}$ do PIDCP (ratificado pelo Marrocos em 1979) e da Convenção contra a tortura e outros tratamentos ou penas cruéis, desumanos ou degradantes (ratificada pelo Marrocos em 1993).

Segundo o relatório da Human Rights Watch de 2019, as autoridades marroquinas continuam a reprimir quaisquer formas de apoio à autodeterminação saaraui, impedindo a atuação de ONGs locais em defesa dos Direitos Humanos, como a Sahrawi Association of Victims of Grave Human Rights Violations Committed by the Moroccan State (ASVDH), e, em algumas situações, chegam a agredir ativistas e jornalistas nas ruas ou quando estão sob sua custódia (HRW, 2019). Essas repressões são respaldadas na constituição marroquina, que proíbe qualquer ataque ou questionamento sobre a integridade territorial. Porém, essas atitudes repressivas são contrárias a dispositivos do PIDCP, que garantem o respeito à liberdade de expressão, associação e assembleia pacíficas (HRW, 2018).

Nos acampamentos de refugiados, administrados pela Frente Polisário com a ajuda da Argélia, a população saaraui vive precariamente, pois a região dos acampamentos na "Hamada” argelina tem um clima severo, a terra não é fértil e é isolada. Atualmente, a população enfrenta um cenário um pouco melhor do que aquela vivida quando começaram a formar os campos. A situação nos mesmos era muito difícil, já que não contavam com nenhum saneamento, havia pouca oferta de comida, epidemias infantis, entre outros problemas. Uma das razões para a relativa melhora nas atuais condições de vida consiste no apoio recebido de outros países e de organizações internacionais como a ONU, por meio do Alto Comissariado das Nações Unidas para Refugiados (ACNUR) (JUSTO 2013).

A população que reside nos campos, das gerações mais velhas às mais novas, mantém um sentimento nacionalista e clama pela sua autodeterminação (UM FIO... 2017). Essas pessoas, além de terem sido forçadas a deixar seu território, separadas das suas famílias, também lidam com a falta de uma nacionalidade, pois, por não pertencerem a nenhum Estado, são consideradas apátridas (violação ao direito à nacionalidade, artigo 15 da DUDH), apesar de se identificarem em uma

\footnotetext{
${ }^{16}$ Dentre as torturas sofridas pelos saarauis estão espancamentos, exposição ao frio, mutilação - como é caso da remoção das unhas, tanto dos pés como das mãos -, violações sexuais utilizando diversos objetos etc. (BERISTAIN; HIDALGO, 2012).
} 
nação, de fazerem parte da RASD e terem um governo eleito. Este estado autoproclamado possui reconhecimento de mais de 80 Estados (SMORALEK, 2013), porém não é um Estado reconhecido de fato no sistema internacional.

A despeito de os campos de refugiados estarem em seu território, a Argélia cedeu a autoridade dos mesmos para a Frente Polisário, sendo esta responsável, portanto, pelos Direitos Humanos da população refugiada. Entretanto, a Frente Polisário não tem nenhum tipo de vínculo jurídico com a comunidade internacional e controla o território de acordo com a constituição e as leis da autoproclamada RASD. Sendo assim, não possui a obrigação de prestar contas à comunidade internacional sobre o que se passa nos campos. E a Argélia, que deveria prestar contas, por fazer parte do seu território, também não o faz. Portanto, segundo a ONG Human Rights Wacth, a situação vivida pelos saarauis se caracteriza como um “limbo legal” (HRW, 2018, p. 09).

Embora a Frente Polisário, ao que se sabe, não reprima violentamente aqueles que a criticam, não há uma oposição política a seu governo, por deter o controle sobre todos os recursos dos campos, ainda que escassos. Em geral, os opositores ao governo Polisário recebem diversas críticas dentro dos campos, por parte da Polisário e do restante da população, porém não há relatos de que a mesma tenha tentado impedir aqueles que queriam deixar os campos. Entretanto, aqueles que pretendem sair o fazem em segredo por medo de alguma represália da Frente Polisário (HRW, 2018).

A Frente Polisário não tem dever legal de cumprir os instrumentos internacionais de Direitos Humanos, por inexistir compromisso jurídico, o que se dá com a assinatura e ratificação dos mesmos. Ademais, à época do conflito armado e mesmo posteriormente, o movimento de libertação foi acusado perante a ONU de infringir os Direitos Humanos da população que representa. Em 2018, numa reunião da Assembleia Geral da ONU, foram ouvidas petições que denunciavam violações de Direitos Humanos por parte do governo marroquino e da Frente Polisário (AG, 2018). Diante disso, a população saaraui se encontra numa situação vulnerável, não tendo a quem recorrer diretamente.

Todas essas violações ou privações de Direitos Humanos, tanto nas Zonas Ocupadas, quanto nas Zonas Livres e nos acampamentos de refugiados configuram desrespeito ao princípio da segurança humana. Nas Zonas Ocupadas, o governo do Marrocos tem sido responsável por violações sistemáticas à população saaraui ao longo dos anos. Neste caso, o Estado - apesar de não ser reconhecida a sua soberania sobre o território - que deveria garantir os direitos desta população é o violador de seus direitos, impedindo, assim, a garantia da segurança humana. Ademais, o Estado marroquino segue impune por seus atos, não tendo havido julgamento ou sanções aplicadas pela comunidade internacional em todos esses anos, mesmo após a institucionalização do conceito da R2P.

Por outro lado, no caso das Zonas Livres e dos acampamentos de refugiados, a população se encontra exilada de seu território e em situação de apatridia, vivendo em condições precárias, em total dependência da ajuda humanitária e sob o governo da Frente Polisário, que não conta com nenhum tipo de oposição ou órgão para fiscalizá-lo. Resta patente, então, que esta população não dispõe de segurança econômica, segurança alimentar, segurança sanitária, segurança ambiental, segurança pessoal, segurança comunitária e segurança política da maneira como deveriam usufruir. Portanto, inobstante o consenso na comunidade internacional de que a segurança humana deva ser prioridade a fim de resguardar a segurança global e evitar novos conflitos, não é o que mostra a situação vivenciada no Saara Ocidental.

O conflito do Saara Ocidental revela a falha da comunidade internacional em sua responsabilidade de proteger. A impunidade acerca de todas as violações cometidas pelo Estado marroquino, por exemplo, requer entendimento sobre a composição do CS, órgão competente para tratar de assuntos de Direitos Humanos enquanto ameaça à Segurança Internacional. Vale lembrar que o órgão possui cinco membros permanentes com poder de veto: EUA, França, Reino Unido, Rússia e China - os quais não raro se pautam pela lógica tradicional do interesse nacional em suas decisões, sendo o caso do Saara Ocidental um exemplo disso.

Os maiores aliados do Marrocos no sistema internacional são EUA e França, o que implica no favorecimento desses Estados às solicitações marroquinas, e explica porque o Marrocos nunca recebeu uma punição por suas atitudes. 
Além disso, dificulta a resolução do conflito. O prolongamento deste seria favorável ao Marrocos, pois em teoria as novas gerações saarauis teriam menos resistência à ideia de anexação ao território marroquino. Entretanto, o que se vê é a resistência passando de geração em geração, tanto na população residente nos campos, quanto na das Zonas Ocupadas, inclusive com a população mais jovem querendo retornar ao conflito armado, como demonstrado no documentário "Um fio..." (2017).

Essa possibilidade reforça a ideia de que questões de Direitos Humanos também são questões de Segurança Internacional. As violações sofridas pela população saaraui há décadas fazem com que esta enxergue como a única solução para a salvaguarda de seus direitos a retomada do conflito armado - o que envolveria não só o Marrocos e a Frente Polisário, podendo transbordar para toda uma rede de alianças de ambos na região. Portanto, a ineficácia em assegurar os Direitos Humanos de toda uma população, como a saaraui, pode levar a um problema mais acirrado de Segurança Internacional e consequentemente gerar ainda maior desrespeito aos direitos fundamentais de indivíduos e coletividades.

Apesar disso, o máximo que tem sido feito pelo CS é a renovação do mandato da MINURSO todo ano, porém esta é a única das missões da ONU que não tem como um de seus propósitos monitorar aspectos relativos a Direitos Humanos. O seu objetivo principal é a realização do referendo de autodeterminação da população saaraui, o que ainda não ocorreu e não há previsão para tanto. Ademais, parte desta população acredita que a missão não está ali para ajudá-los e sim para fortalecer a ocupação marroquina, demonstrando a descrença na comunidade internacional, representada pela operação da ONU (UM FIO... 2017). Descrença esta que não seria infundada, visto ser frequente o uso de intervenções ditas humanitárias que não propiciam na prática a efetivação dos Direitos Humanos das populações civis impactadas, fato já reconhecido internacionalmente e que, como vimos, culminou na proposta do princípio RwP.

É inegável que o pensamento tradicional, focado nos Estados, em sua soberania, em aspectos territoriais, recursos naturais, teses geopolíticas etc., ainda está muito presente no CS. O conflito do Saara Ocidental se insere nesse cenário por ser uma disputa sobre um território que possui muitos recursos naturais, como o fosfato, bancos pesqueiros, areia, aquíferos, diversos minérios, entre eles: cobre, urânio, ferro e zinco e possivelmente petróleo (ES-SWEYIH, 2001; DUARTE, 2016). Tais recursos são explorados pelo Marrocos e empresas estrangeiras no território ocupado - o que é ilegal, pois, segundo as Convenções de Genebra de 1949, a ocupação militar não representa a soberania legal sobre o território. Portanto, os recursos naturais nunca pertenceram ao Marrocos (MARTÍ, 2003).

Os membros permanentes do CS (EUA, França, Reino Unido, Rússia e China) ignoram o princípio da responsabilidade de proteger, em que a comunidade internacional, representada pelo CS, deveria agir a fim de garantir os Direitos Humanos das populações em contextos conflituosos. Isso faz com que o conceito de segurança humana e todo o regime internacional de Direitos Humanos, cuja eficácia depende fortemente desse órgão, mostrem - se frágeis e não raro ineficientes. Ademais, os membros permanentes utilizam desses mecanismos para atingir seus próprios interesses, intervindo e abstendo-se quando julgam necessário. No discurso, os Direitos Humanos são priorizados, com a instituição de normas e princípios como a segurança humana, o R2P e o RwR, mas na prática são instrumentalizados em prol das agendas das grandes potências. Assim, inobstante as mudanças ocorridas no campo da segurança internacional após a Guerra Fria, contemplando aspectos de Direitos Humanos, não houve transformações significativas na situação da população saaraui, que continua sofrendo violações sistemáticas em seus direitos mais fundamentais.

\section{Considerações finais}

O regime internacional de Direitos Humanos foi se desenvolvendo dentro do sistema ONU desde o pós -Segunda Guerra Mundial e conta com órgãos especializados na temática. Porém, estes órgãos, como o Conselho de Direitos Humanos, não têm força punitiva e autoridade para fazer valer o cumprimento das obrigações firmadas pelos Estados - 
razão pela qual atuam mediante recomendações e denúncias. Além disso, os Direitos Humanos eram associados à esfera da segurança nacional e os Estados resistiam a tratá-los com alcance global.

Ao passo que o sistema internacional foi se reconfigurando com o fim da Guerra Fria, a pauta dos Direitos Humanos passa a receber um olhar mais amplo (pensamento ampliacionista), deixando o escopo da segurança nacional (pensamento tradicional) e se alçando ao da Segurança Internacional. Assim, questões de Direitos Humanos se consolidaram como competência do CS, órgão da ONU que tem como principal função manter a paz e a segurança internacional, o qual assumiu papel fundamental em assuntos humanitários.

O conflito do Saara Ocidental foi se desenvolvendo juntamente com essas mudanças. O conflito armado foi palco de diversas violações de direitos humanos e, mesmo após o cessar-fogo, estas continuaram - como demonstramos ao longo do texto. O desrespeito aos Direitos Humanos da população saaraui, tanto nas Zonas Ocupadas, como nas Zonas Livres e nos acampamentos de refugiados, embora se revele sistemático, não têm recebido a devida atenção por parte da comunidade internacional. Não à toa, por este motivo, a população saaraui vê como solução o retorno ao conflito armado, conforme já discutido.

Nesse caso, a despeito das novas formulações conceituais nos campos da segurança internacional e dos direitos humanos, a dificuldade maior é a prevalência do pensamento tradicionalista refletido na estrutura do CS, em que cinco Estados possuem poder de veto e o utilizam como meio de manobra política em favor de seus interesses estatais. Isso é visto nas alianças estatais entre o governo marroquino, os EUA e França, por exemplo, as quais impedem que o CS tome providências efetivas a fim de assegurar os direitos mais básicos dessa população que vem sofrendo há mais de 40 anos. Dessa maneira, este tipo de pensamento e ação no sistema internacional não acompanham as mudanças propostas pelo regime internacional de Direitos Humanos, descaracterizam o seu caráter universal e descumprem os princípios da segurança humana e da responsabilidade de proteger, como podemos constatar no caso em estudo.

\section{Referências}

ANISTIA INTERNACIONAL. Shadow of Impunity: Torture in Morocco and Western Sahara.1\%. ed. London: Amnesty International Ltd, $2015,155 \mathrm{p}$.

ASSEMBLEIA GERAL DA ONU (AG). Resolução 1514 [XV]. AG index: A/RES/1541(XV), 14 de dezembro de 1960. Disponível em: $<$ http://www.un.org >. Acesso em: 11 ago. 2019.

ASSEMBLEIA GERAL DA ONU (AG). Mixed Reviews for Morocco as Fourth Committee Hears Petitioners on Western Sahara, Amid Continuing Decolonization Debate. 2018. Disponível em: $<$ https://www.un.org/press/en/2018/gaspd664.doc.htm $>$. Acesso em: 13 ago. 2019.

ASSOCIAÇÃO DE COOPERAÇÃO E SOLIDARIEDADE ENTRE OS POVOS (ACOSOP). Relatório sobre as Torturas, Violações dos Direitos Humanos e Condições de Saúde - Denunciados pelos 24 Presos Saharauís de Gdeim

Izik no Julgamento de 1, 8 - 16 de fevereiro de 2013 no Tribunal Militar de

Rabat. Marrocos, 2013, 33 p.

BARATA, Maria João Ribeiro Curado. Identidade, Autodeterminação e Relações internacionais: O Caso Do Saara Ocidental. 2012. 348 p. Dissertação (Doutoramento em Política Internacional e Resolução de Conflitos) - Faculdade de Economia da Universidade de Coimbra, Coimbra, 2012. Disponível em: <http://repositorio.ismt.pt/bitstream/123456789/256/1/TESE.pdf>. Acesso em: 15 jul. 2017.

BERISTAIN, Carlos Martín; HIDALGO, Eloísa González. El Oasis De La Memoria: Memoria histórica y violaciones de Derechos Humanos en el Sáhara Occidental

(Tomo I). Bilbao: Hegoa, 2012. Disponível em: <http://publicaciones.hegoa.ehu.es/publications/281>. Acesso em: 15 out. 2017.

BESENYŐ, János. Western Sahara. Pécs: Publikon Publishers, 2009. 198 p.; ZOUBIR, Yahia H.. El Conflicto Del Sahara Occidental En La Geopolítica Magrebí. 2008. Disponível em: <http://iajuws.org/analisis/20080000_YahiaZoubir.pdf?OpenElement>. Acesso em: 31 mar. 2020.

BIERRENBACH, Ana Maria. O conceito de responsabilidade de proteger e o direito internacional humanitário. Brasília: Fundação Alexandre de Gusmão, 2011. 320 p. Disponível em: <http://funag.gov.br/biblioteca/download/884-

Conceito_de_responsabilidade_de_proteger_e_o_Direito_Internacional_Humanitario_O.pdf $>$.Acesso em: 12 mar. 2020. 
BOUKHARI, Ahmed. Las dimensiones internacionales del conflicto del Sahara Occidental y sus repercusiones para una alternativa marroquí. Documento de Trabalho (DT) No 16/2004. 19/4/2004. Disponível em:

$<$ http://www.realinstitutoelcano.org/wps/portal/web/rielcano_es/contenido?WCM_GLOBAL_CONTEXT=/elcano/elcano_es/zonas_es $\lfloor$ mediterraneo+y+mundo+arabe/dt16-2004>. Acesso em: 20 mar. 2020.

BUZAN, Barry, HANSEN, Lene. A Evolução dos Estudos de Segurança Internacional. Trad. Flávio Lira. São Paulo: Editora Unesp, 2012. 576p. ISBN 978-85-393-0266-6.

СOBO, Ignacio Fuente. Sahara Occidental: Origen, evolución y perspectivas de un conflicto sin resolver. Instituto Español de Estudos Estrategicos, 2011. Disponível em: $<$ http://www.ieee.es/publicaciones-new/documentosmarco/2011/DIEEEM08_2011SaharaOccidental.html>. Acesso em 20 set. 2017.

COBO, Ignacio Fuente; MENÉNDEZ, Fernando M. Mariño. El Conflicto Del Sahara Occidental. Madrid: Ministerio de Defensa, Escuela de Guerra del Ejército, Instituto Universitario de Estudios Internacionales, Europeos Francisco de Vitoria, 2006. 220 p. (Serie Conflictos Internacionales Contemporáneos). Disponível em:

$<$ http://portal.uc3m.es/portal/page/portal/inst_fco_vitoria/publicaciones/colec_conflict/monografias>. Acesso em: 14 out. 2017.

CONSELHO DE SEGURANÇA. Relatório 21360. 1990. Disponível em:

<https://peacemaker.un.org/sites/peacemaker.un.org/files/MA_880830_SettlementProposals.pdf>. Acesso em:13 mar. 2020.

CONSELHO DE SEGURANÇA. Relatório 22464. 1991. Disponível em: <https://undocs.org/S/22464>. Acesso em: 13 mar. 2020.

CONSELHO DE SEGURANÇA. Resolução 690. 1991. Disponível em:

<https://www.un.org/ga/search/view_doc.asp?symbol=S/RES/690(1991)>. Acesso em: 13 mar. 2020.

DAUDÉN, Laura; SUZIN, Giovana Moraes. Nem Paz Nem Guerra: Três décadas de conflito no Saara Ocidental. $1^{\circ}$. ed. Rio de Janeiro: Tinta Negra Bazar Editorial, 2011. 232 p.

DUARTE, Geraldine Rosas. O Papel da ONU no Conflito do Saara Ocidental. Revista Conjuntura Austral, Porto Alegre, v. 07, n. 33-34, p.04-15, mar. 2016. Disponível em: <http://www.seer.ufrgs.br/index.php/ConjunturaAustral/article/view/59898/36711>. Acesso em: 20 jul. 2017.

DUARTE, João Paulo Gusmão P.. Uma crítica à ampliação da segurança no pós-guerra fria. Conjuntura Internacional: problematizando o dispositivo da responsabilidade de proteger, Belo Horizonte, v. 12, n. 2, p.123-133, $2^{\circ}$ sem. 2015. Disponível em: <http://periodicos.pucminas.br/index.php/conjuntura/article/view/9377/8970>. Acesso em: 14 mar. 2020.

ESTRADA, Rodrigo Duque. Saara Ocidental: História, Geopolítica e Perspectivas da Última Colônia. Cadernos de Relações Internacionais, [s.1.], v. 7, n. 1, p.118-147, 15 jul. 2014. Faculdades Católicas. http://dx.doi.org/10.17771/pucrio.cadri.23174. Disponível em: <https://www.maxwell.vrac.puc-rio.br/23174/23174.PDFXXvmi >. Acesso em: 13 out. 2017.

ES-SWEYIH, Mohamed-fadel Ould Ismaïl Ould. El primer Estado del Sahara Occidental. Paris: Février, 2001. 139 p. Tradução de: Nathnaîl RABALLAND; Carmen ASTIASO. Disponível em: <http://www.arso.org/1estadosaharaui.pdf>. Acesso em: 31 mar. 2020.

FERREIRA, Sylvio; MIGON, Eduardo. A Estratégia de uma Guerra Esquecida: fundamentos estratégicos aplicados à questão do Saara Ocidental. Revista Política Hoje, Pernambuco, v. 24, n. 2, p. 193-217, dez. 2015. Disponível em:

<https://periodicos.ufpe.br/revistas/index.php/politicahoje/article/view/3727>. Acesso em: 25 mar. 2017.

FIELDS, A. B. Rethinking Human Rights for the New Millenium. New York: Palgrave MacMillan, 2003. Cap. 1: The Birth of the Human Rights Idea and its Detractors.

GARCÍA, Paco Matías. Cooperación y situación humanitaria en los campamentos de refugiados saharauis. In: VICENTE, María Teresa; NAVALÓN, Conrado. El conflicto del Sahara Occidental y los derechos humanos: Miradas desde la Universidad de Murcia. Murcia: Ediciones de La Universidad de Murcia, 2014. Cap. 12. p. 121-132. Disponível em: <http://libros.um.es/editum/catalog/book/1381>. Acesso em: 31 mar. 2020.

GIMÉNEZ, María Teresa Vicente. El estatuto político-jurídico del Sáhara Occidental y los derechos humanos del pueblo saharaui. In: VICENTE, María Teresa; NAVALÓN, Conrado. El conflicto del Sahara Occidental y los derechos humanos: Miradas desde la Universidad de Murcia. Murcia: Ediciones de La Universidad de Murcia, 2014. Cap. 12. p. 121-132. Disponível em: $<$ http://libros.um.es/editum/catalog/book/1381>. Acesso em: 31 mar. 2020.

GHISLENI, A. Direitos Humanos e Segurança Internacional: o tratamento dos temas de Direitos Humanos no Conselho de Segurança das Nações Unidas. Brasília: FUNAG, 2011. Cap. 2. Disponível em:

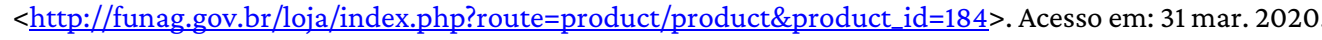

HUMAN RIGHTS WATCH (HRW). La situación de los derechos humanos en el Sahara Occidental y los campamentos de refugiados de Tinduf. 2018. Disponível em: $<$ https://www.hrw.org/sites/default/files/reports/wsahara1208spsumandrecs.pdf>. Acesso em: 13 ago. 2019.

INTERNATIONAL COMMISSION ON INTERVENTION AND STATE SOVEREIGNTY (ICISS). The Responsibility to Protect. Ottawa: International Development Research Centre, 2001. Disponível em: $<$ http://responsibilitytoprotect.org/ICISS\%20Report.pdf $>$. Acesso em: 24 jun. 2020. 
JUSTO, Juan Carlos Gómez. El Frente Polisario: La Historia De Un Movimiento De Liberación Nacional Vivo. Revista Internacional de Pensamiento Político, Huelva, v. 8, n. 7, p.261-280, dez. 2013. Disponível em: < http://hdl.handle.net/10272/8304 >. Acesso em: 22 out. 2017.

KENKEL, Kai Michael. O dilema interno da soberania: A evolução das normas de intervenção. In: KENKEL, Kai Michael; MORAES, Rodrigo Fracalossi de. O Brasil e as operações de paz em um mundo globalizado: entre a tradição e a inovação. Brasília: IPEA, 2012. pp. 19-48. Disponível em: <https://www.ipea.gov.br/portal/index.php?option=com_content\&view=article\&id=16688 $>$. Acesso em: 25 jun. 2020.

KRASNER, Stephen. Structural causes and regime consequences: regimes as intervening variables. International Organization, Cambridge, v. 36, n. 2, p. 185-205, spring, 1982. Disponível em:

<http://www.ir.rochelleterman.com/sites/default/files/krasner\%201982.pdf $>$. Acesso em: 26 mar. 2020.

LARRAMENDI, Miguel Hernando de. La cuestión del Sáhara Occidental como factor de impulso del proceso de descentralización marroquí. Revista de Estudios Internacionales Mediterráneos, Madrid, v. 04, n. 09, p.1-10, dez. 2010. Disponível em: <https://repositorio.uam.es/handle/10486/670255>. Acesso em: 20 jul. 2017.

LÓPEZ, Emiliano Gómez. A República Saharaui, uma história de luta anticolonialista. Espanha, mar. 2012. Disponível em: <https://pt.scribd.com/document/260871767/CARTILHA-Republica-Saharaui\#>. Acesso em: 27 set. 2017.

MARTÍ, Ana María Badia. La explotación de los recursos naturales del Sáhara Occidental: las negociaciones de pesca entre la Unión Europea y Marruecos. El Vuelo de Icaro, Madrid, v. 4, n. 4, p.49-57, mar. 2003. Disponível em:

$<$ http://www.ligaproderechoshumanos.org/icaro/sumario4.html $>$. Acesso em: 13 out. 2017.

MIGUEL, Carlos Ruiz. El Sahara Occidental y España: Historia, Política y Derecho. Madrid: Dykinson, 1995. 401 p.

MUNDY, Jacob; STEPHAN, Maria J. A Battlefield Transformed: From Guerilla Resistance To Mass Nonviolent Struggle In The Western Sahara. Journal of Military and Strategic Studies, [S.1.], 2006. Vol. 8, № 3, p. 32. Disponível em: <https://www.nonviolentconflict.org/wp-content/uploads/2016/02/A-Battlefield-Transformed..From-Guerilla-Resistance-to-Mass-Nonviolent-Struggle-inthe-Western-Sahara.pdf.>. Acesso em: 31 mar. 2020.

OLIVEIRA, A. B. O Fim da Guerra Fria e os Estudos de Segurança Internacional: O Conceito de Segurança Humana. Revista Aurora, Ano III, No. 5, dezembro de 2009. Disponível em: <http://www.marilia.unesp.br/Home/RevistasEletronicas/Aurora/OLIVEIRA.pdf >. Acesso em: 31 mar. 2020.

ORGANIZAÇÃO DAS NAÇÕES UNIDAS (ONU). As Nações Unidas e os Direitos Humanos. Disponível em: $<$ https://nacoesunidas.org/direitoshumanos/sistemaonu/>. Acesso em: 11 ago. 2019.

ORGANIZAÇÃO DAS NAÇÕES UNIDAS (ONU). Carta das Nações Unidas, ONU, 1945. Disponível em: https://nacoesunidas.org/wpcontent/uploads/2017/11/A-Carta-das-Na\%C3\%A7\%C3\%B5es-Unidas.pdf. Acesso em: 31 mar. 2020.

ORGANIZAÇÃO DAS NAÇÕES UNIDAS (ONU). Declaração Universal dos Direitos Humanos. 1948. Disponível em: $<$ https://www.ohchr.org/EN/UDHR/Pages/Language.aspx?LangID=por>. Acesso em: 11 ago. 2019.

ORGANIZAÇÃO DAS NAÇÕES UNIDAS (ONU). Pacto Internacional de Derechos Civiles y Políticos. 1966. Disponível em: <https://www.ohchr.org/SP/Professionalinterest/Pages/CCPR.aspx>. Acesso em: 11 ago. 2019.

ORGANIZAÇÃO DAS NAÇÕES UNIDAS (ONU). Pacto Internacional de Derechos Económicos, Sociales y Culturales. 1966. Disponível em: <https://www.ohchr.org/SP/ProfessionalInterest/Pages/CESCR.aspx>. Acesso em: 11 ago. 2019.

PROGRAMA DE DESENVOLVIMENTO DAS NAÇÕES UNIDAS (PNUD). Human Development Report 1994: New Dimensions of Human Security. 1994. Disponível em: <http://www.hdr.undp.org/en/content/human-development-report-1994>. Acesso em: 25 jun. 2020

QUINTON-BROWN, Patrick. A responsabilidade ao proteger: elemento de ligação ou cavalo de troia para a R2P?. In: HAMANN, Eduarda P. et al (org.). A Implementação da Responsabilidade de Proteger: Novos rumos para a paz e a segurança internacional? Brasília: Instituto Igarapé, 2013. p. 66-72. Disponível em: <https://igarape.org.br/wp-content/uploads/2013/03/eBook_R2P_PT_25mar.pdf>. Acesso em: 14 mar. 2020.

SANTAYANA, Mauro. Dossiê da Guerra do Saara. Rio de Janeiro: Paz e Terra. 1987

SMOLAREK, Adriano Alberto. Conflito no Saara Ocidental: um país além da miragem. Revista Conjuntura Global, Curitiba, v. 2, n. 1, p.34-38, mar. 2013. Disponível em: <http://www.humanas.ufpr.br/portal/nepri/files/2012/04/Conflito-no-Saara-Ocidental-Um-paísalém-da-miragem.pdf $>$. Acesso em: 20 jul. 2017.

STUENKEL, Oliver. O Brasil como articulador de normas: a responsabilidade ao proteger. In: HAMANN, Eduarda P. et al (org.). A Implementação da Responsabilidade De Proteger: novos rumos para a paz e a segurança internacional?. Brasília: Instituto Igarapé, 2013. p. 62-65. Disponível em: <https://igarape.org.br/wp-content/uploads/2013/03/e-Book_R2P_PT_25mar.pdf>. Acesso em: 14 mar. 2020 . 
STUENKEL, Oliver. TOURINHO, Marcos. Regulating intervention: Brazil and the responsibility to protect. Conflict, Security \& Development. 2014. Disponível em: < https://www.tandfonline.com/doi/pdf/10.1080/14678802.2014.930593>. Acesso em: 22 jun. 2020.

UM FIO de esperança: Independência ou Guerra no Saara Ocidental. Direção de Rodrigo Duque Estrada e Renatho Costa. Roteiro: Rodrigo Duque Estrada e Renatho Costa. Música: Lucas Diaz. [s.l.]: Nomos, 2017. (94 min.), son., color. Legendado. Disponível em: $<$ https://www.youtube.com/watch?v=KY1bfcnG3Js\&vl=en>. Acesso em: 20 ago. 2019.

\footnotetext{
Funções de colaboração exercidas

Jéssica Moreira de Amorim Morais

Julia Bertino Moreira
}

Conceituação; Escrita (primeira redação);

Conceituação; Escrita (primeira redação); 